\begin{tabular}{c}
\hline Review of \\
ECONOMICS \\
and \\
INSTITUTIONS
\end{tabular}

\title{
The Impact of Journal Weighting Scheme Characteristics on Research Output Measurement in Economics: The New Zealand Case
}

\author{
David L. Anderson \\ Queen's University \\ University of Waikato
}

\author{
John Tressler \\ University of Waikato
}

\begin{abstract}
In this study we test for the 'power' or aggressiveness of various journal weighting schemes, especially those based on the recursive adjustment methodology first developed by Liebowitz and Palmer. Using data generated by New Zealand's academic economists, we provide quantitative measures of the differences between recursive adjustment-based schemes and selected alternatives. We then compare the performance of economics departments under each of our journal weighting schemes and, for comparison purposes, one based on direct citation counts. We find departmental rankings based on selected recursive adjustment schemes to be relatively stable, but these rankings differed substantially from those generated by our alternative schemes. This suggests that departmental hiring practices and research strategies must be sensitive to the type of funding scheme employed. In particular, research on domestic and regional issues is likely to be unattractive to researchers if a high-powered journal weighting scheme is adopted as the "official" standard since regional journals, the natural outlet for such work, are frequently zero-weighted by such schemes.
\end{abstract}

JEL classification: A14; C81; J24

Keywords: economics departments, research output, research assessment measures, citations, impact factors

The authors would like to thank the referees for valuable suggestions that helped to improve this paper. The usual disclaimer applies.

Corresponding author. Private Bag 3105, Hamilton, New Zealand (Phone +64 (0) 7838-4314. Email: tressler@waikato.ac.nz).

\section{Recommended Citation}

Anderson, D.L., Tressler, J. (2012). The Impact of Journal Weighting Scheme Characteristics on Research Output Measurement in Economics: The New Zealand Case. Review of Economics and Institutions, 3(3), Article 4. doi: 10.5202/rei.v3i3.95.

Retrieved from http://www.rei.unipg.it/rei/article/view/95 


\section{Introduction}

It is becoming relatively common for nations to allocate research funding, at least in part, on the basis of various measures of research output (OECD, 2010). It is also apparent that many governmental funding agencies have adopted, or are considering adopting, bibliographic techniques for generating required measures of institutional performance (Oswald, 2007). Therefore, it is important that both administrators and researchers understand the impact of selected indicators on the resulting output estimates and rankings. We have chosen to examine this issue in the context of one discipline only: economics. More specifically, we will analyze the impact of measuring refereed paper output by utilizing journal-based weighting schemes that are derived from both citation counts and peer judgement ${ }^{1}$. We concentrate on the most commonly utilized measurement schemes in which the quality of citations is also weighted. Furthermore, we will employ data from New Zealand to demonstrate that the choice of a journal weighting scheme can have significant impact on determining winners and losers.

Much of the prior work in measuring the performance of economics departments has been based on a relatively small number of highly cited international journals (for example, see Scott and Mitias, 1996; Dusansky and Vernon, 1998; Kalaitzidakis et al., 1999,2003; and Baltagi, 2007). However, this approach is problematic when conducting a national performance review for the purpose of allocating research funds to help the nation state achieve its economic and social objectives. First, such an approach is likely to lead to a politically untenable solution since it is probable that a small percentage of institutions will capture a lion's share of the available funds. Secondly, and related to the first point, research output with a local or regional focus will be largely ignored in the calculation process since such work tends to be published in regional journals that are not likely to be included in the "top" journal list. Thirdly, it is quite possible that a substantial proportion of a nation's research output will be largely ignored in the measurement process. This follows from the fact that there are over 1300 recognized economics and economics-related journals (as listed in EconLit as at August 2011) and it is rare for more than 200 of these publications to be included in evaluation studies. Therefore, universities must defend the following proposition: that a significant proportion of their total research output is of little or no value to society.

\footnotetext{
${ }^{1}$ It must be stressed that in this paper, and throughout the economics-based output measurement literature, countable research consists only of refereed articles published in a given set of journals (usually a subset of journals listed in EconLit). Obviously, this definition of research ignores many other forms of scholarly output such as books, monographs, conference papers, working papers, and refereed journals not included in the study.
} 
Evaluation schemes that suggest that much research output is of little value because it is not published in a limited number of highly ranked journals is both "bad politics" for institutions that receive a substantial proportion of their total revenue from public sources, and is a difficult position to support from a theoretical position. As the work of Oswald (2007), Wall (2009) and Chang et al. (2011) demonstrates, over time, highly cited papers can be found in lower ranked journals and papers that fail to receive a single cite over a period as long as twenty-five years, can be found in the so-called "top" journals ${ }^{2}$. This suggests that an evaluation system based on a limited number of highly cited international journals is unlikely to generate a socially and politically acceptable solution.

In this paper we examine a number of conventional schemes for measuring research output in the economics literature, and then apply these to economics departments in a small nation state - New Zealand. In the next section we discuss the evolution of journal-based research measurement schemes in economics in the post-1984 period - the start of the prevailing system for adjusting citations to account for various factors. Section 3 contains information on the New Zealand university system, a discussion of our underlying dataset, and a rationale for the various assumptions employed in the analysis. Our results are contained in Section 4, and this is followed by our concluding comments.

\section{Literature Review}

\subsection{Basic Citation-based Impact Factors}

The impact factor concept can be traced back to Garfield (1972), and gained importance with the computerization of the Social Science Citation Index (SSCI) database (now known as the Thomson Reuters ISI Web of Science, or more commonly as the ISI $)^{3}$. The definition of an impact factor is exceedingly simple: the total number of citations from journals in year $t$ to articles published in year's $t-1$ and $t-x$, divided by the number of articles published by the receiving journal in year's $t-1$ to $t-x$ where $x$ can range from 2 to the number of years the journal has been in publication. However, in practice, a journal's impact factor is frequently calculated with " $t$ " set at 2 years. This is the definition used by ISI for deriving its best known set of journal impact factors, commonly called the "Journal Citation Report (JCR)

${ }^{2}$ For a general discussion of the limitations of the peer review process that contribute to this result, see Starbuck (2005).

${ }^{3}$ Henceforth we shall use the term ISI to represent the current and former (such as SSCI) databases now more formally known as the Thomson Reuters ISI Web of Science. For details, see http://thomsonreuters.com/products_services/science/science_products/az/web_of_science/ 
2 year impact factors" (henceforth denoted as JCR2IF) ${ }_{4}^{4}$

However, the suitability of a two year citation attribution period is questionable for economics, and, more generally, the social sciences. Given the normal time period required for manuscript preparation, refereeing, revision, and publication, a two year cut-off for citations seems extremely tight (Tressler and Anderson, 2012). The two year lag structure was developed in the context of the biological sciences, a discipline with publication practices and lags much different than those prevailing in economics. Nevertheless, because of its widespread use, we shall use JCR2IF as our representative basic citation-based journal weighting scheme.

Before moving on, we should mention that JCR2IF weights are based on citations from all journals in the ISI database to the selected economics journals. Furthermore, as shown in Table 1, note that JCR2IF yields standardized scores (wherein the top ranked journal receives a score of 100 and all others are adjusted accordingly) of 27.7, 21.9 and 15.1 for $30^{\text {th }}, 50^{\text {th }}$ and $90^{\text {th }}$ ranked journals. It will be subsequently shown that this scheme is relatively generous in its treatment of medium and lower ranked journals.

\subsection{Adjusted Impact Citation Factors}

Arguably the single most influential paper in the citation-based, journal weighting literature is the work of Liebowitz and Palmer (1984) in which the authors attempted to address the major weakness of prior approaches: the implicit assumption that all journals (and the articles therein) are of equal value. To redress this situation, Liebowitz \& Palmer utilized 1980 citation data from the ISI database to generate a ranking of 108 economics journals ${ }^{5}$. They adopted a recursive adjustment process that grants more weight to citations from highly cited journals than less cited journals ${ }^{6}$. The Liebowitz and Palmer methodology continues to serve as the underpinnings of a number of schemes employed in the rankings literature to the present time.

Their recursive adjustment process results in a rather sharp decline in the weights attached to high end journals versus medium and lower ranked periodicals. For example, as shown in Table 1, Liebowitz \& Palmer found that the $30^{\text {th }}$ placed journal receives a score of 8.957 . In other words, it takes slightly more than eleven articles in the $30^{\text {th }}$ ranked journal to equal one in the Journal of Economic Literature (the highest ranked journal). Furthermore,

\footnotetext{
${ }^{4}$ See Garfield (2003) for a discussion of the origins of the impact factor concept, and for Journal Citation Report (JCR) impact factor calculation process see: http://thomsonreuters.com/products_services/science/science_products/a$\mathrm{z}$ /journal_citation_reports/. For a current discussion of various research assessment measures (RAM) based directly or indirectly on impact factors, see Chang et al. (2011).

5 The journals selected for inclusion in this study are almost exclusively those classified by ISI as economics journals as at 1980.

6 See Appendix A for details.

7 In this section of the paper, we have selected the article, rather than the page as the appropriate scale adjustment procedure.
} 
since the $50^{\text {th }}$ and $90^{\text {th }}$ ranked journals receive scores of 2.29 and 0.12 , it takes approximately 43 and 833 articles, respectively, to generate an output level equivalent to having one article in the top ranked journal. We denote this journal weighting scheme as LP84.

It should be noted that Liebowitz and Palmer only counted citations from economics journals on the selected list (108 journals) to other journals on the same list. In other words, the end result is a very narrowly defined "economic" impact measure; not only does it ignore the citations from noneconomic journals in the ISI database to our 108 selected journals, it also ignores citations from all other refereed economics and economics-related journals (now in excess of 1300 according to EconLit) to the LP84 list of recognized economics journals 8

Table 1 - Characteristics of Selected Journal-based Weighting Schemes

\begin{tabular}{|c|c|c|c|c|c|c|c|c|}
\hline & LP84 & LP94 & KMS & KYEI & RePEc & JCR2IF & ERA & EQUAL \\
\hline Year Published or Year of Version Utilized & 1984 & 1994 & 2003 & 2006 & 2009 & 2008 & 2010 & 2011 \\
\hline Journals in Calculation & 108 & 130 & 143 & 181 & 540 & 209 & 640 & $+/-1300$ \\
\hline$\%$ of Total Output from Top30 Journals & 97.1 & 97.2 & 88.9 & 82.2 & 72.6 & 53.6 & N/A & N/A \\
\hline$\%$ of Total Pages Given non-zero weighting & 26.8 & 29.5 & 39.3 & 48.3 & 63.3 & 50.9 & 94.3 & 100.0 \\
\hline Active Researchers as a \% of Total Researchers & 49.6 & 54.1 & 62.2 & 64.4 & 68.1 & 67.4 & 77.8 & 77.8 \\
\hline Gini Coefficient & 0.92 & 0.93 & 0.90 & 0.87 & 0.79 & 0.71 & 0.28 & 0.00 \\
\hline \multicolumn{9}{|l|}{ Standardized Weight of: } \\
\hline -30th Ranked Journal & 8.95 & 6.10 & 7.84 & 12.39 & 20.97 & 27.66 & B & 100.00 \\
\hline -60th Ranked Journal & 2.29 & 2.10 & 3.87 & 5.46 & 13.94 & 21.87 & B & 100.00 \\
\hline -90th Ranked Journal & 0.12 & 0.10 & 0.76 & 2.18 & 6.85 & 15.06 & C & 100.00 \\
\hline
\end{tabular}

Liebowitz and Palmer's work was updated by Laband and Piette (1994). They utilized SSCI data from 1990, and calculated "recursive adjusted citation" weights for 130 economics journals?. More specifically, Laband and Piette counted 1990 citations in the selected journals to articles published in these same 130 journals over the five year period 1985 to 1989. They then employed the Liebowitz and Palmer methodology to generate a set of updated weights (henceforth denoted as LP94 weights) that have been widely utilized in ranking studies until relatively recently (Kalaitzidakis et al., 2003; Macri and Sinha, 2006; and Sinha et al., 2010).

Although the LP94 ranking of individual journals differs somewhat from that of LP84 due to distinct time periods (1984-1989 versus 1974-1979) and the expansion of the recognized journal list (130 versus 108), the overall nature of the weighting scheme remains the same. For example, under LP94,

8 For a general critique of the Liebowitz and Palmer methodology, see Engemann and Wall (2009).

9 Laband and Piette (1994), with a few minor adjustments, adopted the ISI economics journal list. 
the $30^{t h}, 50^{t h}$ and $90^{t h}$ journals receive weights of $6.1,2.1$ and 0.1 , respectively. Rephrased, it takes approximately 1000 articles in the $90^{\text {th }}$ placed journal to equal one in the most highly ranked journal.

Over time, the LP94 scheme lost some of its lustre for the simple reason that its weights were based on "old" citation data (1990) and its journal list did not include a number of newer publications covering emerging areas within the discipline. This led Kalaitzidakis et al. (2003) to update the work of Liebowitz and Palmer (1984) and Laband and Piette (1994). They utilized the 1998 ISI database to count citations in all 159 ISI listed economics journals to articles published over the 1994-1998 period in these same journals. Kalaitzidakis, Mamuneas and Stengos followed the Liebowitz and Palmer methodology with one exception: they corrected for self-citations (citations from a journal to an article previously published by the same journal).

After adjusting for self-citations and size, Kalaitzidakis, Mamuneas and Stengos generated non-zero weights (henceforth denoted as KMS weights) for 143 journals. As mentioned previously, the years covered for citation collection and the list of journals differs somewhat from that of the LP84 and LP94 studies; nevertheless, the general nature of the weighting schemes remains the same. For example, we find that the $30^{t h}, 50^{\text {th }}$ and $90^{\text {th }}$ journals possess KMS weights of 7.84, 3.87 and 0.76 , respectively. It should be noted that the KMS weighting scheme has come to be seen, in the eyes of many, as the industry standard (Macri and Sinha, 2006; Henrekson and Waldenstrom, 2011) and has been extensively utilized in ranking studies (for example, see Neri and Rodgers, 2006; Anderson and Tressler, 2008a and 2011; Sinha et al., 2010; Mukhopadhyay and Sarkar, 2010; and Henrekson and Waldenstrom, 2011).

After Liebowitz and Palmer's (1984) ground-breaking paper, arguably the most important work in the development of the basic Liebowitz and Palmer model is that of Kodrzycki and Yu (2006). They utilized 2003 ISI citation data covering papers published over the eight year period 1996 to 2003 in selected journals. Kodrzycki and Yu made a number of adjustments to the Liebowitz and Palmer methodology that addressed some of the limitations of the initial recursive adjustment model. First, Kodrzycki and Yu used their own judgement to generate a list of journals widely utilized by economists rather than relying almost exclusively on the JCR classification system. More specifically, they selected 146 of the 169 journals listed as "economics journals" on the JCR (2003) website, and an additional 35 journals from nine other JCR categories for a total of 181 journals. Although subjective, the selection process acknowledges the fact that it is exceedingly difficult to precisely determine the boundary between economics and noneconomics articles in areas such as finance, regional science, psychology, management, and public policy. Although we acknowledge the growing importance of the boundary issue, we have followed convention and restricted economics-relevant journals to those recognized by EconLit. In 
the New Zealand case this list is broad enough to encompass virtually all publications produced by the nation's academic economists over the time period of this study. Nevertheless, the ISI list of "economics" journals is quite restrictive and serves as the basic data source for four of our weighting schemes: LP84, LP94, KMS and KYEJ ${ }^{10}$.

Kodrzycki and Yu's second modification of the Liebowitz and Palmer approach was to correct for differences in reference intensity between the various sub-disciplines of economics. For example, papers on finance and econometric topics contain, on average, substantially more citations than those in economic history. Therefore, finance and econometric journals, everything else being equal, will exhibit larger impact factors than those in economic history. To address this problem, Kodrzycki and Yu employed the adjustment procedure developed by Palacios-Huerta and Volij (2004) ${ }^{11}$. We have labelled this scheme as KYEI, where "EI" stands for economic impact $^{12}$

Let us now look at the nature of the journal weights generated by KYEI. As shown in Table 1 the relevant KYEI scores for the $30^{\text {th }}, 50^{\text {th }}$ and $90^{\text {th }}$ journals are 12.39, 5.46 and 2.18, respectively. Of particular note is the fact that the KYEI estimates do not decline as sharply as those generated by LP84, LP94 and KMS; for these schemes, the $90^{t h}$ ranked journal generated a weight of $0.12,0.10$ and 0.76 , respectively. Although all of these studies employ the Liebowitz and Palmer methodology, Kodrzycki and Yu utilized a broader set of journals, a longer period for collecting citations, a different time period for analysis, and an adjustment for differences in citation practices across sub-disciplines; any one or more of these factors could account for the above noted differences.

\subsection{Other Schemes Provided for Comparative Purposes}

All of the above schemes utilize the ISI database in addition to a common methodology - the Liebowitz/Palmer recursive adjustment model. In order to assess the impact of employing a more extensive database and dif-

${ }^{10}$ Alternative sources exist, such as RePEc (www.RePEc.org) (to be discussed later in this paper) and Scopus (www.scimagojr.com), that cover a broader range of journals and hence address, to some extent, the interdisciplinary nature of modern economics.

11 Adjustment for potential biases in citation patterns between disciplines and subdisciplines is now well established. For examples, see the Scopus-Scimago databases (www.scimagojr.com) for various schemes.

12 Kodrzycki and Yu (2006) generated three weighting schemes denoted as: Economic Impact; Policy Impact; and Overall Impact. We have selected the Economic Impact measure for study since it is based on the traditional Liebowitz and Palmer model. KYEI differs from the other two schemes in that it is based on citations from economics journals (as defined by Kodrzycki and Yu) to the same set of economics journals. The other schemes allow for citations from a broader set of journals (policy journals in one case and all social science journals in the ISI database in the other case) to Kodrzycki and Yu's list of economics journals. 
ferent citation counting practices, but retaining the basic elements of the recursive adjustment model, we have included the "Recursive Discounted Impact Factors for Journals" scheme developed by IDEAS/Research in Economics Papers (RePEc) ${ }^{13}$. This scheme, henceforth denoted as RePEc, follows a similar weighting procedure to Liebowitz and Palmer so that each citation is weighted by the impact factor of the citing item recursively. In addition a further adjustment is made for the age of the citation by dividing by the age of the citation (plus one $)^{14}$. As shown in Table 1 , the $30^{t h}, 50^{\text {th }}$ and $90^{\text {th }}$ journals received standardized scores of 21.0, 13.9 and 6.9, respectively, and thus exhibit a more modest rate of decline than the Liebowitz/Palmer based schemes, but less so than that associated with JCR2IF (a basic two year impact factor scheme based on the ISI database).

At the opposite end of the objectivity scale from recursive adjustment schemes are those generated by surveys of "experts". Although the use of reputational surveys to generate a set of journal rankings appears to have fallen out of favour after manipulation friendly versions of the ISI database became available (and now Google Scholar and Scopus databases), there are exceptions ${ }^{15}$. The scheme we have chosen for study purposes is Australia's Excellence in Research for Australia (ERA). The ERA allows us to address two important issues. First, it allows us to contrast outcomes between pure and partial citation-based schemes and those based on perceptions of a journal's worth and reputation. Second, the use of an Australasian journal-based weighting scheme allows us to explore a contentious issue in small and medium sized nations, especially those outside of the Europe and North American-the relative importance attached to local and regional journals versus international journals. In the case of New Zealand, only one domestic journal is available to the nation's economists- the New Zealand Economic Papers (NZEP). However, many of Australia's journals tend to publish articles on New Zealand matters and hence the ERA can be considered as a proxy scheme for exploring the impact of using regionally sensitive journal weights as opposed to those with a focus on international journals.

As part of the Australian government's effort to evaluate research in all of the nation's universities, the Australian Research Council (2010) developed the ERA- a journal classification scheme based, ultimately, on the judgement of "experts" (Vanclay, 2011; Moosa, 2011). It should be noted that the journal-based ranking scheme was only one of several indicators that was used in the initial nation-wide evaluation exercise 16 . Under the

${ }^{13}$ The version used in this study was downloaded from the organizations website on 23 January 2009 (http:/ /ideas.repec.org/top/top.journals.rdiscount.html).

${ }^{14}$ For details see Zimmermann (2007).

${ }^{15}$ Arguably the best know reputation scheme is that developed by Mason et al. (1997). We have chosen to exclude it from this study due to the age of the study and its USA-centric focus.

${ }^{16}$ For details on the 2010 scheme, see the Excellence in Research for Australia programme's official website at www.arc.gov.au/era (15 August 2010). 
ERA programme ${ }^{17}$ journals are allocated to one of four categories: $\mathrm{A}+, \mathrm{A}, \mathrm{B}$ and $C$ (and some are not ranked at all). With respect to the discipline of economics, 640 journals were formally recognized ${ }^{18}$. The percentage of journals assigned $\mathrm{A}+$ through $\mathrm{C}$ is $7.8,17.5,27.0$ and $47.7 \%$.

For purposes of this paper, we have assigned a grade of 4 to an $\mathrm{A}+$, and so on to a 1 for a C. Economics journals not officially recognized by the ERA, but listed in EconLit, are given a grade of 0 . Therefore, in reality, the ERA ranking scheme is based on a five-point scale. We must stress that the numerical weights are ours, not those of the ERA. At this point we should note one distinguishing feature of the ERA, at least with respect to economics: the explicit attempt to recognize the role of national and regional journals in generating research of importance and relevance to Australia. In total, eleven Australian-produced journals are listed under the economics grouping of the ERA scheme.

The final journal-based weighting scheme to be included in this study is based on the assumption that all journal-based output is of equal value (we label this scheme as EQUAL). More specifically, this means that we will treat all journals as being of equal value, and ultimately all articles and pages of articles as being of equal value. This is really an indicator of quantity, but it is included to provide a reference point- an indication of how much the results generated by other weighting schemes differ from that associated with the extreme assumption that all papers in EconLit listed journals are of equal value.

Before concluding this section, we wish to add another scheme to the "other" category: a direct citation indicator of performance. More specifically, we will estimate the number of non-self ISI citations generated by each researcher's share-adjusted papers. This additional measure, to be noted as CITNS, has been added for comparison purposes since the direct citation approach, and its many variants, continue to attract the attention of economists, especially with respect to the ranking of individual economists (for example, see Engemann and Wall, 2009; Chang et al., 2011; and Ravallion and Wagstaff, 2011). To summarize, we now have a total of eight journal-based weighting schemes. In broad terms, they can be categorized as follows: recursive adjusted citation (LP84, LP94, KMS, KYEI and RePEc); basic citation (JCR2IF); reputational (ERA); and other (EQUAL).

\footnotetext{
${ }^{17}$ Although the Australian Government announced on 30 May 2011 that the journal-based weighting component of the ERA programme will not be utilized in the next evaluation round in 2012 (Moosa, 2011), the ERA journal weighting scheme nevertheless provides us with a recently developed, regionally sensitive, perception-based system.

${ }^{18}$ Although 640 of the 1300 plus journals listed in EconLit were assigned to the "economics" classification, many other journals recognized by EconLit are included in other ERA categories such as "Banking, Finance and Investment", "Urban and Regional Planning" and "Policy and Administration".
} 


\section{Institutional and Database Information}

In order to demonstrate the impact of our selected weighting schemes in a real-world setting, we have chosen New Zealand, a small country of four million people, with eight public universities ${ }^{19}$ and 135 economists (in 2009) Virtually all of the nation's academic economists are to be found in economics departments or in joint economics and finance departments, all within business schools ${ }^{21}$. Although we were unable to find any studies that compared the performance of New Zealand's academic economists to those in other similar sized nations, comparisons with Australian economics departments and individual economists are available, although somewhat dated. The primary source of comparative information is to be found in an extensive study by Macri and Sinha (2006) ${ }^{22}$, they ranked the performance of 25 Australian economics departments and seven in New Zealand ${ }^{23}$ over the period 1988 to 2002. Although Macri and Sinha (2006) found that Australian departments occupied the top eight positions, the New Zealand departments performed marginally better overall (p.135-136). Macri and Sinha (2006) also constructed an "Economists' Hall of Fame, 1988-2002". Five of the 30 individuals listed are New Zealand-based, with the top New Zealand performer being ranked $11^{\text {th }}$ overall, but second over the second half of the evaluation period (1996-2002). On a global scale, the 2012 QS World Rankings of Economics and Econometric Departments suggest that New Zealand's universities perform very well ${ }^{24}$. Six of the nation's eight departments are ranked in the top 200, with Auckland in the 51-100 group, Waikato and Otago in the 101-150 category and Canterbury, Massey and Victoria in the 151-200 band.

The relative performance of New Zealand's academic economists can also be gleaned by reference to the Research Papers in Economics (RePEc) website (www.repec.org). Although the RePEc database is still at the experimental/development stage, and only contains information on those that

${ }^{19}$ The short-form names of the institutions are: Auckland, Auckland Institute of Technology, Canterbury, Lincoln, Massey, Otago, Victoria and Waikato.

${ }^{20}$ For more detailed information on New Zealand's academic economics profession, see Millmow (2011) and Anderson and Tressler (2008b).

${ }^{21}$ This point must be stressed since in some countries many economists have primary appointments in research centres and institutes and/or have economics departments in both business schools and in Arts faculties. This, as noted above, is not the New Zealand situation where virtually all full-time academic economists are employed in business schools in either stand-alone departments or joint economics/finance departments.

${ }^{22}$ Additional comparative information on New Zealand and Australian economists' research performance can be found in Sinha et al. (2010) and Macri and Sinha (2010).

${ }^{23}$ The discrepancy between the earlier figure of eight universities and the seven universities included in Macri and Sinha (2006) is due to the fact that the Auckland University of Technology only came into being in 2000.

${ }^{24}$ For details, see http://www.topuniversities.com/university-rankings/worlduniversity-rankings/2012/subject-rankings/social-science/economics?page=7. 
self-register, it does provide a rough and ready guide as to research performance on a large number of measures. At the time of writing (15 August 2012), 32,909 economists had registered with RePEc. In the overall category (average rank score), the leading New Zealand economist placed in the top 4 percent, and in the top 5 percent in 16 of the available 33 categories. Two other economists placed in the top 6 percent overall and in the top 5 percent in 11 and 5 categories, respectively. In summary, of the top ten New Zealand economists included in this study, as ranked by RePEc, eight are ranked in the top 10 percent overall, and seven placed in the top 5 percent in five or more of RePEc's 33 performance categories. Although it is difficult to draw strong conclusions from the RePEc data, it is our opinion that the more prolific New Zealand economists are internationally competitive.

Table 2 - Journals that Published 7 or More Papers Authored by New Zealand-Based Economists

\begin{tabular}{|c|c|c|c|c|c|c|c|c|c|}
\hline \multirow{2}{*}{ Name of Journal } & \multirow{2}{*}{$\begin{array}{c}\text { Num } \\
\text { of } \\
\text { Articles }\end{array}$} & \multirow[b]{2}{*}{ ERA } & \multicolumn{7}{|c|}{$\begin{array}{c}\text { Weighting Scheme } \\
\text { (Most Highly Ranked Journal = 100.0) }\end{array}$} \\
\hline & & & LP84 & LP94 & KMS & KYEI & RePEc & JCR2IF & EQUAL \\
\hline New Zealand Econ Papers & 28 & $\mathrm{C}$ & 0.00 & 0.00 & 0.00 & 0.00 & 0.00 & 0.00 & 100.00 \\
\hline Economics Letters & 9 & A & 1.61 & 3.00 & 18.73 & 2.40 & 4.22 & 9.57 & 100.00 \\
\hline J of Economic Surveys & 9 & $A$ & 0.00 & 0.00 & 0.00 & 1.49 & 13.54 & 14.50 & 100.00 \\
\hline Rev of Applied Economics & 8 & C & 0.00 & 0.00 & 0.00 & 0.00 & 0.00 & 0.00 & 100.00 \\
\hline Intn J of Industrial Org & 8 & $A$ & 0.00 & 5.20 & 4.26 & 3.68 & 8.84 & 21.30 & 100.00 \\
\hline Rev of Ec Res on Copyright & 7 & $\mathrm{C}$ & 0.00 & 0.00 & 0.00 & 0.00 & 0.00 & 0.00 & 100.00 \\
\hline J of Interdisciplinary Econ & 7 & $\mathrm{C}$ & 0.00 & 0.00 & 0.00 & 0.00 & 0.00 & 0.00 & 100.00 \\
\hline Economics Bulletin & 7 & $\mathrm{C}$ & 0.00 & 0.00 & 0.00 & 0.00 & 0.52 & 0.00 & 100.00 \\
\hline Pacific Economic Bulletin & 7 & $\mathrm{C}$ & 0.00 & 0.00 & 0.00 & 0.00 & 0.00 & 0.00 & 100.00 \\
\hline
\end{tabular}

Note: for $E R A$, the available classifications are from highest to lowest: $A+, A, B, C$.

We conclude our institutional coverage by exploring the type of journals publishing papers written, in whole or part, by New Zealand-based economists. As shown in Table 2, the New Zealand Economic Papers (NZEP), the nation's only academic economics journal, is the favoured publication vehicle for New Zealand- based economists. Other journals containing seven or more articles written in whole or in part by the nation's economists are listed along with the journals ranking in each of our weighting schemes. It is apparent that, with the exception of Economics Letters, and to a lesser extent, the Journal of Economic Surveys and the International Journal of Industrial Organization, the most favoured journals are not highly ranked, and in several cases, such as for NZEP, they are unranked by all of our citation-based schemes. However, it should also be noted that New Zealand economists do, on occasion, publish in leading journals. For example, over the period 2003-2008, they published one or more articles in nine of the top ten KMS ranked journals.

The above information does point, however, to a major problem facing designers of publicly funded research reimbursement schemes. Weighting schemes based directly or indirectly on citations are not likely to rank regional journals highly, especially journals from small or medium sized 
Table 3 - Australasian Journals that Published New Zealand-Based Economists (2003-2008)

\begin{tabular}{lcccccccc}
\hline \hline & \multirow{2}{*}{$\begin{array}{c}\text { Num } \\
\text { Name of Journal }\end{array}$} & & & \multicolumn{4}{c}{$\begin{array}{c}\text { Weighting Scheme } \\
\text { (Most Highly Ranked }=100.0 \text { ) }\end{array}$} \\
\cline { 4 - 9 } & Articles & ERA & LP84 & LP94 & KMS & KYEI & RePEc & JCR2IF \\
\hline New Zealand Economic Papers & 28 & $\mathrm{C}$ & 0.00 & 0.00 & 0.00 & 0.00 & 0.00 & 0.00 \\
Pacific Economic Bulletin & 7 & $\mathrm{C}$ & 0.00 & 0.00 & 0.00 & 0.00 & 0.00 & 0.00 \\
Aust J of Labour Economics & 6 & $\mathrm{~B}$ & 0.00 & 0.00 & 0.00 & 0.00 & 0.00 & 0.00 \\
Economic Record & 6 & $\mathrm{~A}$ & 0.98 & 0.10 & 2.93 & 0.60 & 1.96 & 15.06 \\
Aust Economic Review & 6 & $\mathrm{~B}$ & 0.00 & 0.00 & 0.00 & 0.00 & 1.13 & 6.52 \\
Aust J of Agr \& Resource Economics & 5 & $\mathrm{~A}$ & 0.01 & 0.10 & 0.44 & 0.52 & 0.49 & 14.24 \\
Aust Economic History Rev & 4 & $\mathrm{~A}$ & 0.00 & 0.00 & 0.89 & 0.00 & 0.00 & 8.38 \\
Aust J of Regional Studies & 4 & $\mathrm{~B}$ & 0.00 & 0.00 & 0.00 & 0.00 & 0.00 & 0.00 \\
Agenda & 3 & $\mathrm{C}$ & 0.00 & 0.00 & 0.00 & 0.00 & 0.00 & 0.00 \\
Aust Economic Papers & 3 & $\mathrm{~B}$ & 0.00 & 0.00 & 0.00 & 0.00 & 0.76 & 14.74 \\
\hline \hline
\end{tabular}

Note: for ERA, the available classifications are from highest to lowest: $A+, A, B, C$.

countries. In the New Zealand case, if any one of the above citation-based weighting schemes were to become the "official" weighting scheme, the incentive to publish articles in the NZEP and, to some extent, other Australasian journals, will be severely reduced. As shown in Table 3, the ERA (Australian government's official scheme) journal rankings given to the NZEP, and the other Australasian-based journals that periodically publish articles by New Zealand researchers, are substantially higher than those granted by the citation-based schemes included in this study. Indeed, in most situations the Australasian journals are unranked by international schemes. Despite this situation, the Australian Government announced on 30 May 2011 that the journal ranking component of the ERA programme would not be utilized in the next evaluation round in 2012 (Moosa, 2011) due, in part, to a concern that the scheme did not sufficiently reward regionally-focused research.

In constructing our database, we adopted the prevailing approach on a number of matters that are themselves somewhat controversial 25 . For example, we have defined research to be articles published in journals listed in EconLit, over the period 1 January 2003 to 31 December 200826. A six year evaluation period was chosen since it is the time span used in many national evaluation schemes such as New Zealand's Performance-Based Evaluation Fund (PBRF) ${ }^{27}$. For multi-authored papers, shares have been allocated on the basis of the $1 / \mathrm{n}$ rule where $n$ is the number of authors on the paper. An

${ }^{25}$ For more information on the assumptions employed in constructing the database, see Anderson and Tressler (2008a).

${ }^{26}$ Given the lag between the publication of a refereed paper and the release of a citing article, it is unrealistic to use the same publication period that we have used for measuring refereed paper output (2003-2008). Instead, we have adopted a two year lag between initial publication date and the start of the citation collection period. Therefore, we have counted all non-self ISI citations to papers published over the six year period 2001-2006.

${ }^{27}$ For information about this nation-wide research assessment scheme, see Goldfinch (2003) and Hodder and Hodder (2010). 
equally important allocation rule pertains to the process for assigning refereed papers to departments; we have chosen the Stock method, as opposed to the Flow method, whereby all of an individual researchers' output (over the 2003-2008 period) is assigned to her/his employer as at 15 April 2009.

A more contentious choice is that related to the appropriate unit of output. Once again, we have adopted the prevailing approach, and have selected the size adjusted page as the relevant measure of output. This decision is based on the premise that long papers are, on average, of greater significance than short papers. Given that we have selected the page as our output measure, we will again follow industry norms and convert all pages into American Economic Review (AER) equivalents. Fortunately, we have benefited from the generosity of Sinha and Macri who provided us with their page correction factors for over 500 journals ${ }^{28}$

\section{Results}

In this section we use our New Zealand database to assess differences between the selected journal weighting schemes. We then consider the implications of utilizing these schemes to measure the research performance of New Zealand departments of economics over the period 2003-2008.

The selected journal weighting schemes differ in three principal ways. First, journals are frequently ranked in different order. For example, amongst the journals in which New Zealand economists published between 2003 and 2008, the American Economic Review is ranked $1^{\text {st }}$ by KMS and ERA (along with 24 other journals), $3^{\text {rd }}$ by LP84, $6^{\text {th }}$ by LP94, KYEI and JCR2IF, and $16^{\text {th }}$ by RePEc. Second, schemes differ in terms of their convexity or power, i.e. in terms of their implicit judgement of the relative quality of high and low ranked journals. This issue will be addressed in detail below. Third, the range of journal coverage varies greatly across weighting schemes: for example, LP84 ranks only 108 journals while ERA covers over 600 publications.

In Table 1 we present various descriptive statistics to provide the reader with an appreciation of the degree of aggressiveness of each of our selected schemes. First, let us examine the percentage of output per indicator that is generated by the top thirty journals utilized by New Zealand's economists, as ranked by each weighting scheme ${ }^{29}$. As expected, our recursive adjust-

${ }^{28}$ By using Sinha/Macri page correction factors, we were able to adjust for page size differentials for 178 of the 244 journals utilized by NZ academics during the period 2003-2008. Those journals for which we lacked page correction factors were almost always unranked or ranked in the lowest possible category by all of our selected weighting schemes. For these journals, we used 0.72, the average page correction factor for Gibson's (2000) lowest ranked journal group.

${ }^{29}$ We must stress that by Top30 journals, we mean the thirty most important journals for each of the selected weighting schemes. That is, the Top30 for one scheme will often be quite different from the Top30 under an alternative scheme. Furthermore, we should 
ment impact schemes based on the ISI database are in a class by themselves; in all cases, over $82 \%$ of total output is attributable to the Top30 journals. On the other hand, our basic impact citation scheme, JCR2IF, exhibits a substantially lower estimate (54 percent).

Second, consider the percentage of total size-adjusted pages that receive a non-zero weighting. The results range from 27 percent for LP84 to 94 percent for ERA ${ }^{30}$. To place this information in perspective, it should be noted that only 26 percent of the papers produced by New Zealand economists over the 2001-2006 period received one or more non-self ISI citations by the end of the collection period (31 December 2008) ${ }^{31}$. A third way of addressing the degree of aggressiveness of our various schemes is to ask the following question: what percentage of the nation's academic economists can be considered to be research active? By research active we mean an academic who has published, in whole or in part, at least one paper over the evaluation period that generates a positive output score. From Table 1 note that under LP84 fewer than half of New Zealand's academic economists are deemed to be research active, whereas under ERA and EQUAL more than three quarters of the sample group have attained that status. In addition to providing an insight on the nature of the various weighting schemes, this measure also has political significance since university administrators undoubtedly wish to portray the view that most academics are actively engaged in research.

Let us now explore the aggressive/passive weighting issue in a more rigorous fashion. In Table 1 we also display the relevant Gini coefficient for each weighting scheme ${ }^{32}$. The data closely follows the patterns displayed by

clarify the phrase "as utilized by New Zealand's economists". This means that we have selected the top thirty journals (for each weighting scheme) that contain at least one article published over the period 2003 to 2008 that was authored, in whole or in part, by a staff member (as at 15 April 2009) of a New Zealand economics department.

${ }^{30}$ It should be noted that we have opted for a broad as opposed to a narrow definition of relevant journals with respect to the ERA journal weighting scheme. That is, as long as a journal is listed in EconLit, we assign it the relevant ERA weighting regardless of the discipline category to which it was arbitrarily assigned. For example, researchers with publications in the Journal of Finance and Regional Studies are given the grade assigned to them in their home discipline categories. The "narrow" approach is to grant recognition only to journals listed under the economics discipline, and to ignore the many journals in "border" areas such as finance, urban and regional studies and policy.

31 Although this figure is distressing low, it must be stressed that approximately 44 percent of the refereed journal articles generated by New Zealand economists, albeit over a slightly different time period (2000-2008), were published in journals not included in the ISI database (see Tressler and Anderson, 2012). It should also be noted that if we add back self-cites, the estimate increases to 29.2 percent. To place this figure in context, note that Chang et al. (2011) found that, on average, 26 percent of the articles published in the top 40 economics journals (based on ISI 2 year impact factors), over the period 1988-2010, failed to capture a single cite, even from the paper's author(s). In fact, 20 percent of the selected journals had "no citation" rates in excess of 40 percent.

32 The Gini coefficients presented herein are calculated over the weights of the journals in which New Zealand economists published during the period of this study. That is, they are not Gini coefficients calculated over the weights of all possible economics journals or 
the descriptive statistics discussed above. The greatest degree of inequality is associated with the five recursive adjustment impact schemes. It should also be mentioned that, in general, for this group of schemes, the larger the number of journals covered, the lower the estimated degree of inequality. It is also important to note that ERA exhibits a Gini coefficient that is substantially lower than those exhibited by any other scheme in our study (0.28) with the exception of EQUAL that is, by definition, zero.

The differences between the powers of the schemes can be formally described using Lorenz curves as shown in Figure $1^{33}$. These curves plot the percentage of journals ranked from the lowest to the highest against the percentage of total weight allocated. In the literature on income inequality an income transfer from a poorer to a richer person is said to worsen inequality. A definition of income inequality that corresponds to such transfers coincides with the Lorenz Criteria, i.e. if a Lorenz curve lies everywhere below (weakly) another, then it describes a more unequal income distribution ${ }^{34}$ Similarly, if a transfer of weight from a low ranked journal to a high ranked journal characterises an increase in power, then a scheme with a Lorenz curve that is everywhere below (weakly) another would describe a scheme that is unambiguously more powerful ${ }^{35}$

The comparison of schemes in terms of power generally follows the Gini coefficients. However, RePEc and JCR2IF cannot be unambiguously compared as the Lorenz curves cross. Although it is not obvious from Figure 1 the curves for KYEI and KMS also cross in the range of highly ranked journals. The following unambiguous comparisons from highest to lowest power follow: LP94, KMS, JCR2IF, ERA and LP94, KMS, RePEc and ERA ${ }^{36}$. The citation based schemes are unambiguously more powerful. The Lorenz curves make the influence of this aspect of power clear.

Let us now examine the impact of our various weighting schemes on estimates of departmental research output. In Table 4 we display the performance of New Zealand's eight economics departments under all of the previously discussed weighting schemes. Note that over the 2003 to 2008 period, 105 of New Zealand's 135 academic economists published, in whole or in part, at least one article in a journal listed in EconLit. At this point we must state that we have standardized the results for each output measure (the weighted number of share adjusted, AER equivalent, pages per capita)

over the pages published by New Zealand economists.

${ }^{33}$ The Lorenz curves for LP84 and LP94 are quite similar, thus only LP94 is shown in the diagram to avoid clutter. It is important to note that the order of journals is not the same for different schemes. Differences in order are not represented in the Lorenz curves.

${ }^{34}$ See, for example, Atkinson (1970).

${ }^{35}$ For a recent paper on the theory of Lorenz curve comparisons see Chiu (2007). This theory draws from the literature on stochastic dominance and income inequality. For an application to research evaluation using citations see Ravallion and Wagstaff (2011).

${ }^{36}$ Including KYEI in place of KMS the following unambiguous comparisons are possible: LP94, KYEI, RePEc, ERA and LP94, KYEI, RePEc and ERA. 
Figure 1 - Lorenz Curves, Journals with Publications by New Zealand Economists, (2003-2008)

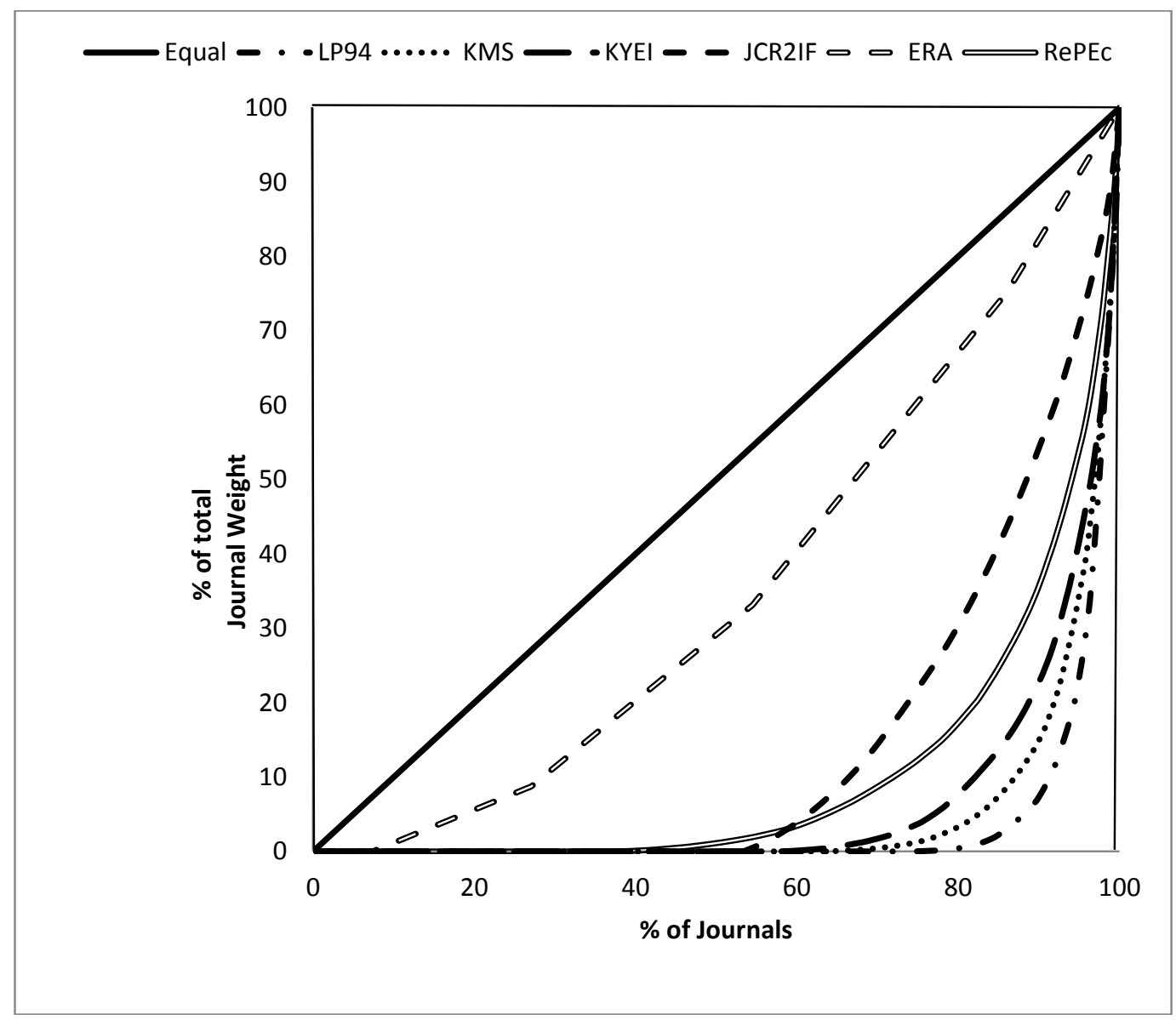

so that the leading institution receives a score of 100, and all other numbers represent a given department's score as a percentage of the leading department's level of attainment.

Perhaps the best place to start our performance review is to look at the winners: Auckland leads in five categories, Waikato in three, and Canterbury in one. First, consider Waikato's performance in more detail; it "wins" when output is measured by the two schemes with the lowest Gini coefficients and in the number of non-self ISI citations per staff member (CITNS). Waikato also does well when output is measured by our basic citation-based impact factor (JCR2IF) - it is in a virtual tie with Auckland with a score of 98.8. This suggests that Waikato fares well under "low" and "medium" powered journal-based weighting schemes. In summary, Waikato does well under schemes that are relatively egalitarian in nature.

The situation for Auckland is somewhat different. It exhibits the highest share-adjusted page count per capita on four of our five recursive adjustment schemes (LP84, LP94, KMS, and RePEc). Although Auckland does 
Table 4 - Normalized Departmental Scores: Weighted Pages Per Capita (2003-2008)

\begin{tabular}{lccccccccc}
\hline \hline & LP84 & LP94 & KMS & KYEI & RePEc & JCR2IF & ERA & EQUAL & CITNS \\
\hline Auckland & 95.5 & 100.0 & 100.0 & 100.0 & 100.0 & 100.0 & 54.3 & 39.8 & 35.1 \\
AUT & 1.7 & 0.5 & 1.9 & 4.4 & 13.5 & 25.2 & 52.3 & 45.8 & 22.0 \\
Canterbury & 100.0 & 28.4 & 40.0 & 68.9 & 54.5 & 86.3 & 60.7 & 49.3 & 40.7 \\
Lincoln & 16.2 & 1.7 & 1.7 & 2.6 & 4.7 & 14.5 & 18.0 & 27.9 & 12.4 \\
Massey & 3.6 & 0.9 & 2.9 & 2.2 & 3.6 & 15.3 & 24.2 & 25.4 & 14.7 \\
Otago & 54.0 & 9.2 & 14.2 & 21.7 & 34.6 & 63.4 & 57.7 & 46.2 & 53.1 \\
Victoria & 95.9 & 54.0 & 47.0 & 88.6 & 61.9 & 88.8 & 49.0 & 36.2 & 32.0 \\
Waikato & 17.4 & 2.3 & 15.6 & 22.0 & 33.5 & 98.8 & 100.0 & 100.0 & 100.0 \\
Average & 48.0 & 24.6 & 27.9 & 38.8 & 38.3 & 61.5 & 52.0 & 46.3 & 38.8 \\
\hline
\end{tabular}

extremely well under so-called "strong" weighting schemes, it is interesting to note that their academic staff generate only 35 percent as many non-self ISI citations per capita as do staff members at Waikato ${ }^{37}$.

It is clear that if the New Zealand government were to adopt a research funding model based, in whole or in part, on any of our selected journalweighted schemes, the two schools mentioned above would have a lot to gain or lose. Indeed, all schools would have reason to lobby for either strong or weak weighting schemes if research funding is to be allocated on the basis of any of the schemes utilized in this study.

Let us now look at the general relationship between our chosen weighting schemes. In Table 5 we present the pair-wise correlation coefficients for the previously discussed departmental output data. For discussion purposes, we shall focus on the relationship of our seven journal-based measures with our two reference schemes. What stands out is the weak relationship between EQUAL and the five recursive adjustment impact schemes in this study. In fact, the relevant correlation coefficients range from -0.18 to +0.09 . This further suggests that schemes based on the Liebowitz and Palmer methodology can be considered powerful weighting vehicles. At the other extreme, the correlation coefficient for ERA/EQUAL is 0.94.

Table 5 - Pairwise Correlation Coefficients, Departmental Output, Weighted Pages Per Capita (2003-2008)

\begin{tabular}{|c|c|c|c|c|c|c|c|c|c|}
\hline & LP84 & LP94 & KMS & KYEI & RePEc & JCR2IF & ERA & EQUAL & CITNS \\
\hline LP84 & 1.00 & 0.79 & 0.81 & 0.94 & 0.87 & 0.74 & 0.17 & -0.10 & 0.06 \\
\hline LP94 & & 1.00 & 0.98 & 0.92 & 0.94 & 0.64 & 0.06 & -0.18 & -0.07 \\
\hline KMS & & & 1.00 & 0.93 & 0.97 & 0.72 & 0.19 & -0.05 & 0.06 \\
\hline KYEI & & & & 1.00 & 0.95 & 0.79 & 0.22 & -0.04 & 0.08 \\
\hline RePEc & & & & & 1.00 & 0.84 & 0.36 & 0.09 & 0.22 \\
\hline JCR2IF & & & & & & 1.00 & 0.75 & 0.55 & 0.67 \\
\hline ERA & & & & & & & 1.00 & 0.94 & 0.94 \\
\hline EQUAL & & & & & & & & 1.00 & 0.95 \\
\hline CITNS & & & & & & & & & 1.00 \\
\hline
\end{tabular}

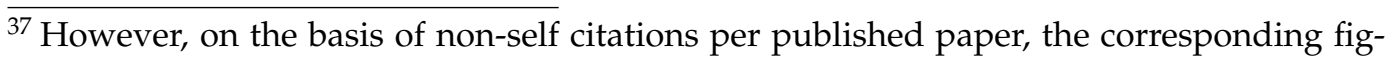
ures for Auckland, Waikato and the system-wide average are 1.29, 0.91 and 1.06, respectively. 
The second metric to focus on is CITNS, our measure of non-self ISI citations per capita. Note that the correlation coefficients for EQUAL/CITNS and ERA/CITNS are 0.95 and 0.94, respectively. At the other extreme, we find the corresponding coefficients for LP94/CITNS and KMS/CITNS to be -0.07 and 0.06 . At this point all we can say is that if all ISI citations are of equal value, and if the preferred method of evaluating a paper's impact is the number of direct citations it receives, then, in the New Zealand context, schemes based on the Liebowitz and Palmer methodology yield problematic outcomes. Finally, we note that the evaluation of research outputs based on the perceived quality of journals (ERA) ${ }^{38}$ corresponds more closely with that based on un-weighted direct ISI citations (CITNS) than those based on recursive adjustment citation schemes.

\section{Conclusion}

The rationale for our study is the belief that more and more nations will adopt bibliographic techniques as a short-cut for measuring the level of research output in their nation's universities, and that the results of this exercise will be used, at least in part, to allocate funding between the competing institutions. This led us to test the applicability of various citation-based journal weighting schemes as instruments for measuring economic research output in the context of a nation-wide research funding model. To do so, we divided the task into two elements. First, we discussed the evolution and nature of citation-based journal weighting schemes, with particular attention paid to those based on the recursive adjustment citation methodology first developed by Liebowitz and Palmer (1984). Second, we tested selected weighting schemes by using data generated by academic economists located in economics departments of New Zealand's universities.

If our premise is correct, it is vitally important that all actors involved understand the implications of using one journal-based weighting scheme over another in the prevailing institutional context. From a given university's perspective, it is important for researchers and administrators to understand how the journal selection process affects the output performance and, hence, research funding. From the public granting agency's perspective, it is important that the selected scheme encourage activity in line with government's goals and objectives. For example, is research on local and regional issues of importance to the nation state; and, if so, does the journal weighting scheme reward such activity? Similarly, does the journal weighting system reward economists for their contribution to public policy debates or does it primarily reward economists for making a contribution to the dis-

\footnotetext{
${ }^{38}$ At this point we must remind the reader that the weighting scheme used for ERA is our own: we have transformed the official schemes letter grade scheme into a numerical scheme as follows: $\mathrm{C}=1 ; \mathrm{B}=2 ; \mathrm{A}=3$ and $\mathrm{A}+=4$. Journals listed in EconLit but not recognized by ERA receive a weighting of zero.
} 
cipline of economics?

Our findings suggest that the quantity / quality issue, as traditionally defined, is an important one for all concerned. More formally, we explored this issue in the context of strong versus weak journal weighting schemes. Recall that all four of the recursive adjustment citation schemes based on the ISI database displayed Gini coefficients in the 0.87 to 0.93 range, whereas RePEc, JCR2IF, ERA, and EQUAL exhibited coefficients of 0.79, 0.71, 0.28, and 0.00 , respectively. Clearly some schemes are less egalitarian than others. We also found that under ERA (and of course, by definition, EQUAL) virtually all research output was deemed to be of value, whereas under the ISI-based recursive adjustment citation schemes only 27 to 48 percent of published pages were given a non-zero weighting. Similarly, we found that only 26 percent of published papers in our database had received one or more non-self ISI citations. In other words, under some schemes the majority of pages (and papers) produced were, in effect, deemed to be worthless.

In a recent study, employing a number of research assessment measures (RAM) similar to those used in this study, Henrekson and Waldenstrom (2011) found that the output rankings of individual Swedish economists were quite sensitive to the type of RAM utilized in the analysis. They conclude their study with the following quote: "Therefore, the choice of measures is of great importance unless it emerges that the ranking and relative valuation of different researchers and departments is largely invariant with respect to an array of output measures. The evidence presented in this study speaks strongly against any presumption of this sort' ${ }^{39}$. Our departmental results also suggest that the weighting scheme selection process does matter to those involved. It is clear from our departmental analysis that two departments in New Zealand dominate the ranking game: Auckland and Waikato lead in five and three of our nine categories, respectively. Waikato was seen to do very well under our so-called "weak" schemes, and Auckland performs exceedingly well under the "strong" schemes. This suggests that if New Zealand were to implement a journal weighting scheme for measuring research output for the purpose of allocating funding, university administrators should not be indifferent between approaches. They have much to lose or gain depending upon their research strategies.

There are a number of qualifications to our work. First, we have utilized the ISI database throughout the study. It is possible that the use of a competing scheme such as Google Scholar or Scopus would lead to different results. We leave it to others to argue the relative merits of various databases. Second, we have followed convention and have restricted countable research

\footnotetext{
${ }^{39}$ At this point we should stress that although there are some similarities between the studies, Henrekson and Waldenstrom (2011) measure and rank the life-time research output of Swedish Professors. In our study, we measure departmental research output for all universities in New Zealand produced by all academic staff (lecturer and up) over the time span normally employed in nation-wide research assessment schemes (six years).
} 
to work published in refereed economics journals, often narrowly defined both with respect to subject and number. We acknowledge that other forms of scholarship ideally should be included such as citations to books, conference papers and working papers; however, they have been ignored for pragmatic reasons and in this regard we have once again followed convention. Third, our findings are based on the performance of New Zealand's academic economists over the period 2003 to 2008. Hence, our results may be time specific and are definitely discipline specific. Fourth, New Zealand is a very small country with only eight university-based economics departments; therefore the transferability of our findings to larger domains is open to question and further study.

In conclusion, we agree with Engemann and Wall (2009) that "There is no such thing as the correct ranking of economics journals. Instead, there is a universe of rankings, each the result of a set of subjective decisions by its constructor." However, it is important for all participants to understand the nature of possible weighting schemes they may face, and to either adjust their research practices accordingly if they wish to participate successfully in the research funding arena, and/or to lobby for measurement systems that reward activities they deem appropriate for both academia and society at large. 


\section{References}

Anderson, D.L., Tressler, J., 2008a. Research Output in New Zealand Economics Departments 2000-2006. New Zealand Economic Papers 42, 155189. doi:10.1080/00779950809544420

Anderson, D.L., Tressler, J., 2008b. An Analysis of New Zealand Economists' Research Output 2000-2006. Working Paper 20/08, Economics Department, University of Waikato, Hamilton, New Zealand.

Anderson, D.L., Tressler, J., 2011. Ranking Economics Departments in Terms of Residual Productivity: New Zealand Economics Departments, 2000-2006. Australian Economic Papers 50, 157-168. doi:10.1111/j.14678454.2011.00418.x

Atkinson, A.B., 1970. On the Measurement of Inequality. Journal of Economic Theory 2, 244-263. doi:10.1016/0022-0531(70)90039-6

Australian Research Council. 2010. Excellence in Research for Australia. Retrieved from www.arc.gov.au/era, 15 August 2010.

Baltagi, B.H., 2007. Worldwide Econometrics Rankings: 1989-2005. Econometric Theory 23, 952-1012. doi:10.1017/S026646660707051X

Chang, C.L., McAleer, M., Oxley, L., 2011. What Makes a Great Journal Great in Economics? The Singer not the Song. Journal of Economic Surveys 25, 326-361. doi:10.1111/j.1467-6419.2010.00648.x

Chiu, W.H., 2007. Intersecting Lorenz Curves, the Degree of Downside Inequality Aversion, and Tax Reforms. Social Choice and Welfare 28, 375-399. doi:10.1007/s00355-006-0170-7

Dusansky, R., Vernon, C.J., 1998. Rankings of U.S. Economics Departments. Journal of Economic Perspectives 12, 157-170. doi:10.1257/jep.12.1.157

Engemann, K.M., Wall, H.J., 2009. A Journal Ranking for the Ambitious Economist. Federal Reserve Bank of St. Louis Review 91, 127-139.

Garfield, E., 1972. Citation Analysis as a Tool in Journal Evaluation. Science 178, 471-479. doi:10.1126/science.178.4060.471

Garfield, E., 2003. The Meaning of the Impact Factor. International Journal of Clinical and Health Psychology 3, 363-369.

Gibson, J., 2000. Research Productivity in New Zealand University Economics Departments: Comments and Update. New Zealand Economic Papers 34, 73-87. doi:10.1080/00779950009544316 
Goldfinch, S., 2003. Investing in Excellence? The Performance-Based Research Fund and its Implications for Political Science Departments in New Zealand. Political Science 55, 39-53. doi:10.1177/003231870305500104

Henrekson, M., Waldenstrom, D., 2011. How Should Research Performance be Measured? A Study of Swedish Economists. Manchester School 79, 1139-1156. doi:10.1111/j.1467-9957.2010.02216.x

Hodder, A.P.W., Hodder, C., 2010. Research Culture and New Zealand's Performance-Based Research Fund: some insights from bibliographic compilations of research outputs. Scientometrics 84, 887-901. doi:10.1007/s11192-010-0201-0

Kalaitzidakis, P., Mamuneas, T., Stengos, T., 1999. European Economics: An Analysis Based on Publications in the Core Journals. European Economic Review 43, 1150-1168. doi:10.1016/S0014-2921(99)00019-7

Kalaitzidakis, P., Mamuneas, T., Stengos, T., 2003. Rankings of Academic Journals and Institutions in Economics. Journal of the European Economic Association 1, 1346-1366. doi:10.1162/154247603322752566

Kodrzycki, Y.K., Yu, P., 2006. New Approaches to Ranking economics Journals. B.E. Journal of Economic Analysis and Policy: Contributions to Economic Analysis and Policy 5, Article 24.

Laband, D., Piette, M., 1994. The Relative Impact of Economics Journals. Journal of Economic Literature 32, 640-666.

Liebowitz, S.J., Palmer, J.P., 1984. Assessing the Relative Impact of Economics Journals. Journal of Economic Literature 22, 77-88.

Macri, J., Sinha, D., 2006. Rankings Methodology for International Comparisons of Institutions and Individuals: An Application to Economics in Australia and New Zealand. Journal of Economic Surveys 20, 111-156. doi:10.1111/j.0950-0804.2006.00277.x

Mason, P., Steagall, J., Fabritius, M., 1997. Economics Journal Rankings by Type of School: Perceptions Versus Citations. Quarterly Journal of Business and Economics 361, 69-79.

Millmow, A., 2011. Our Friends across the Ditch: A Brief Sketch of the New Zealand Academic Economic Profession. Economic Papers 30, 273278. doi:10.1111/j.1759-3441.2011.00103.x

Moosa, I., 2011. The Demise of the ARC Journal Ranking Scheme: an Ex-Post Analysis of the Accounting and Finance Journals. Accounting and Finance 51, 809-836. doi:10.1111/j.1467-629X.2011.00432.x 
Mukhopadhyay, T., Sarkar, S., 2010. Rankings of Economics Journals and Departments in India. Working Paper 2010-021, Indira Gandhi Institute of Development Research, Mumbai, India.

Neri, F., Rodgers, J.R., 2006. Ranking Australian Economics Departments by Research Productivity. Economic Record 82, S74-S84. doi:10.1111/j.14754932.2006.00334.x

OECD. (2010). Performance- based Funding for Public Research in Tertiary Education Institutions. Workshop Proceedings. OECD Publishing. doi:10.1787/9789264094611-en.

Oswald, A.J., 2007. An Examination of the Reliability of Prestigious Scholarly Journals: Evidence and Implications for Decision-Makers. Economica 74, 21-31. doi:10.1111/j.1468-0335.2006.00575.x

Palacios-Huerta, I., Volij, O., 2004. The Measurement of Intellectual Influence. Econometrica 72, 963-977. doi:10.1111/j.1468-0262.2004.00519.x

Ravallion, M., Wagstaff, A., 2011. On Measuring Scholarly Influence by Citations. Scientometrics 88, 321-337. doi:10.1007/s11192-011-0375-0

Scott, L.C., Mitias, P.M., 1996. Trends in Rankings of Economics Departments in the U.S.: An Update. Economic Inquiry 34, 378-400. doi:10.1111/j.1465-7295.1996.tb01383.x

Sinha, D., Macri, J., McAleer, M., 2010. On the Robustness of Alternative Rankings Methodologies: Australian and New Zealand Economics Departments, 1988-2002. Applied Economics 42, 1257-1268.

Starbuck, W.H., 2005. How much Better are the Most-Prestigious Journals? The Statistics of Academic Publication. Organization Science 16, 180-200. doi:10.1287/orsc.1040.0107

Tressler, J., Anderson, D.L., 2012. Using Citations to Measure Research Output in New Zealand Economics Departments: The problem of 'Long and variable' Lags. Agenda: A Journal of Policy Analysis and Reform 19, 17-37.

Vanclay, J.K., 2011. An Evaluation of the Australian Research Council's Journal Ranking. Journal of Informetrics 5, 265-274. doi:10.1016/j.joi.2010.12.001

Wall, H.J., 2009. Don't Get Skewed Over by Journal Rankings. B.E. Journal of Economic Analysis and Policy: Topics 9, Article 34.

Zimmermann, C., 2007. Academic Rankings with RePEc, Working Paper 2007-36, Department of Economics Working Paper Series, University of Connecticut, Storrs, Connecticut, U.S.A. 


\section{Appendix A}

\section{The Liebowitz-Palmer (LP) Model}

The details of the calculation are as follows. Initially Liebowitz and Palmer calculate the number of citations from all journal articles published in 1980, in all journals in the SSCI database (approximately 4200 in 1980), to each of 108 economics journals. The countable cites are restricted to those generated by articles published over the 1975-1979 period (denoted as the age adjustment procedure). The resulting estimates can be labelled as the "unadjusted impact citation" values. These are used to report rankings based on "Citations per Article Published" (Liebowitz and Palmer, 1984, see Table1).

This procedure includes citations from non-economic and less influential economic journals. Thus Liebowitz and Palmer calculate "adjusted impact citation" weights by counting citations only from economics journals and through the use of an iterative or recursive process that weights citations by a quality weight for the citing journal that itself is based on its citation based impact factor. Using similar notation to Liebowitz and Palmer the procedure can be described as follows:

$$
Q_{i h}=\sum_{j=1}^{n} C_{i j} Q_{j h-1}
$$

where

$$
Q_{i 0}=\sum_{j=1}^{m} C_{i j}
$$

$Q_{i h}=$ the impact adjusted value for journal $i$ in iteration $h$,

$C_{i j}=$ the number of citations to journal $i$ from journal $j$,

$m=$ the number of journals in SSCI, and

$n=$ the number of economics journals.

Thus in the first iteration citations are adjusted by the number of citations from all the SSCI journals to the citing journal, while in subsequent iterations citations are weighted by the impact adjusted value for the citing journal calculated for the previous iteration. This iterative process is continued until the impact values converge or approximately reach a "fixed point". Liebowitz anad Palmer report journal rankings based on impact adjusted citations obtained after 50 iterations.

To adjust for the size of journals the Liebowitz and Palmer suggest two approaches: first, to simply divide the adjusted impact citation value by the number of articles published by each journal in 1980; or second, to generate an estimate of the number of adjusted impact citations per typed character. 
Rankings based on impact adjusted citations per article and per character are provided.

Researchers applying the Liebowitz and Palmer methodology have adapted it in a variety of ways with variations in the adjustment of citations and the normalisation of the measures. For a more generic presentation of the recursive adjustment scheme, both in descriptive and mathematical form, see Mukhopadhyay and Sarkar (2010). 